\title{
GESTÃO DA CADEIA DE SUPRIMENTOS: UMA ANÁLISE SOBRE AS MODALIDADES DE AQUISIÇÃO NO SETOR PÚBLICO, SUAS FALHAS E SUGESTÕES PARA UMA REPOSIÇÃO DE ESTOQUE MAIS EFICIENTE JUNTO AO SETOR DE FARMÁCIA
}

\author{
Claudia Regina Siqueira \\ Universidade Federal Fluminense \\ MBA Logística Empresarial e Gestão da Cadeia de Suprimentos
}

Fatima Auxiliadora Bezerra Lima Romi

Universidade Federal Fluminense

Mestrado em Sistemas de Gestão - LATEC

\begin{abstract}
Aurélio Lamare Soares Murta
Universidade Federal Fluminense

Programa de Pós-Graduação em Administração - PPGAd
\end{abstract}

Martius Vicente Rodriguez y Rodriguez

Universidade Federal Fluminense

Programa de Pós-Graduação em Administração - PPGAd

Joel de Lima Pereira Castro

Universidade Federal Fluminense

Programa de Pós-Graduação em Administração - PPGAd 


\begin{abstract}
RESUMO
Este artigo tem o objetivo apontar as diferenças e adequar os procedimentos básicos de aquisições adotados na iniciativa privada às aquisições realizadas setor público, tornando-os mais eficientes. Práticas que, reconhecidamente, otimizam recursos financeiros e o capital humano. Há décadas, o profissional de compras, em especial na Administração Pública é ignorado nas fases de planejamento. Tal profissional é visto como mero executor de tarefas administrativas. Na administração gerencial moderna, a valorização do capital humano e o investimento em organização e controle passam a fazer parte do planejamento estratégico das Instituições. Após pesquisas bibliográficas, demonstra-se que uma organização não se resume a produtos e tecnologia de ponta. As pessoas são as principais agentes de mudanças e responsáveis diretas nos resultados obtidos, sejam eles positivos ou negativos.
\end{abstract}

\begin{abstract}
This article aims to point out the differences and adapt the basic procurement procedures used in the private sector to the public sector, making the acquisitions more efficient. These practices of optimizing financial resources and human capital are acknowledged. For decades, buyers in procurement department, especially in Public Administration have been ignored in the planning stages. This professional is seen as a mere executor of administrative tasks. In modern management administration, the optimisation of human capital and the investment in organization and control become part of the strategic planning of the institutions. After bibliography researches, it was proved that an organization is not limited to products or cutting-edge technology. People are the main change agents and directly responsible for the results, whether positive or negative.
\end{abstract}




\section{Sustainable Business \\ International Journal}

SBIJ72 - MARÇO DE 2017 - ISSN 1807-5908

\section{INTRODUÇÃOO}

Uma organização não se resume a produtos, tecnologia de ponta, instalações físicas. As pessoas são as principais agentes de mudanças e responsáveis diretas nos resultados obtidos, sejam eles positivos ou negativos. Na Administração Pública a responsabilidade do colaborador torna-se ainda maior, pois os agentes públicos atuam diretamente na gestão da aplicação dos recursos vindos, em sua maioria, do pagamento de impostos feitos pela sociedade.

A Cadeia de Suprimentos na Administração Pública está diretamente associada a funções rígidas. Mesmo de maneira tímida este panorama vem sofrendo alterações. A administração burocrática e retrógrada tende a iniciar uma fase moderna e gerencial, voltada para os resultados.

Utilizando a metodologia de pesquisas bibliográficas, são apresentados conceitos da área logística e cadeia de suprimentos, administração pública, administração hospitalar e formas de aquisição na administração pública que fundamentam a possibilidade e necessidade de modernização.

A gestão moderna tem como base a flexibilização e a visão holística, ou seja, as organizações, e principalmente uma Unidade Hospitalar funciona como um sistema, um organismo vivo, onde não existem ações isoladas. 


\section{Sustainable Business International Journal}

O objetivo deste estudo não é esgotar um assunto tão complexo, mas iniciar uma reflexão ou mesmo um debate sobre o novo perfil dos processos de aquisição e a necessidade de modernização na administração dos recursos públicos.

\section{LOGÍSTICA E CADEIA DE SUPRIMENTOS - CONCEITOS}

Conceito difundido pelo Council of Logistics Management (CLM) define Logística como "O processo de planejamento, implantação e controle do fluxo eficiente e eficaz de mercadorias, serviços e das informações relativas desde o ponto de origem até o ponto de consumo com o propósito de atender as exigências dos clientes”. Inicialmente a questão da logística era tratada de forma fragmentada dentro das empresas, tendo um mesmo assunto várias nomenclaturas tais como: distribuição, distribuição física, administração de materiais, logística de distribuição, segundo Lambert (1998).

Ballou (2006, p. 29) define cadeia de suprimentos como "um conjunto de atividades funcionais (transportes, controle de estoques, etc) que se repetem inúmeras vezes ao longo do canal pelo qual matérias-primas vão sendo convertidas em produtos acabados, aos quais se agrega valor ao consumidor".

O conceito defendido por Novaes (2007, p. 38) apresenta a cadeia de suprimentos como o "caminho que se estende desde as fontes de matéria-prima, passando pelas fábricas dos componentes, pela manufatura do produto, pelos distribuidores e chegando finalmente ao 


\section{Sustainable Business International Journal}

consumidor através do varejista”.

Outros autores defendem conceitos acerca de Gerenciamento da Cadeia de Suprimentos. Para Fleury (1999) o Gerenciamento da Cadeia de Suprimentos é muito mais completa, compreendendo o desenvolvimento do produto, além de compras e desenvolvimento de fornecedores. Ganeshan e Harrison (2012) conceituam Supply Chain Management - SCM como uma rede de serviços e opções de distribuição que desempenha as funções de aquisição de materiais, transformação desses materiais em produtos intermediários e acabados, bem como a distribuição desses produtos acabados para os clientes. Para Dornier et al. (2000, p. 369) a "gestão da cadeia de suprimentos é a gestão de atividades que transformam as matérias-primas em produtos intermediários e produtos finais, e que entregam esses produtos finais aos clientes".

Um ponto que parece ser consenso entre muitos autores é o conceito de uma gestão coordenada, com atividades interligadas em detrimento de uma visão fragmentada de processos.

\section{ADMINISTRAÇÃO PÚBLICA - ALGUMAS CONSIDERAÇÕES A RESPEITO DE ADMINISTRAÇÃO PÚBLICA.}

Para Meirelles, Administração Pública consiste em um conjunto de Instituições que tem como objetivo auxiliar ao Governo, ou agir em nome deste, em funções necessárias a manutenção 


\section{Sustainable Business International Journal}

dos serviços públicos em geral, nos âmbitos municipal, estadual ou federal. (MEIRELLES, 1990, apud GARCIA, 2008).

A Administração Pública pode ser Direta ou Indireta. A Administração Direta é formada por pessoas jurídicas denominadas entidades: União, Estados, Distrito Federal e Municípios. Tais entidades atuam diretamente por meio de seus órgãos nos Poderes Executivo, Legislativo e Judiciário. Na Administração Indireta ocorre a descentralização. Quando as entidades diretas não agem diretamente por intermédio de seus Órgãos, são criadas outras entidades. São exemplos de entidades da Administração Pública Indireta as Autarquias, Fundações, Empresas Públicas e Sociedades de Economia Mista. Estas entidades são criadas com características próprias. São vinculadas as entidades da Administração Direta, porém não há subordinação. (MEIRELLES, 1990).

A Constituição Federal define as diretrizes do Serviço Público, os Princípios que regem a Administração Pública Direta e Indireta - Legalidade, Impessoalidade, Moralidade, Publicidade e Eficiência. Além disso, a lei 8.666 de 21 de junho de 1993 regulamenta o art. 37, inciso XXI, da Constituição Federal, instituindo normas gerais para licitações e contratos administrativos pertinentes a obras, serviços, inclusive de publicidade, compras, alienações e locações no âmbito dos Poderes da União, dos Estados, do Distrito Federal e dos Municípios.

\subsection{Teoria da Burocracia na Administração Pública}

A Administração Pública é um dos mais complexos campos, e nela são encontradas várias 


\section{Sustainable Business International Journal}

Teorias Administrativas. A corrente mais facilmente identificável é a Teoria da Burocracia de Max Weber, desenvolvida no decorrer dos anos 40. De acordo com Chiavenato, para Weber havia a necessidade de um modelo de organização racional capaz de caracterizar todas as variáveis envolvidas, assim como o comportamento dos seus membros diante do tamanho e complexidade das empresas.

A Teoria da Burocracia era o oposto do que a palavra "Burocracia" costuma representar atualmente. O termo é empregado com sentido de restrição a regulamentos, rotinas maçantes, ineficiência, atrasos. O autor ainda defende que para Weber a Burocracia é a organização eficiente por excelência. E, para que isso aconteça, é necessário um detalhamento antecipado das tarefas. Dentre as principais características da Teoria da Burocracia podem-se destacar: organizações geridas por regulamentos e normas por escrito; formalidade nas comunicações; racionalidade e divisão do trabalho; relações impessoais; distribuição das tarefas feita de acordo com cargos e funções, desconsiderando as pessoas envolvidas; hierarquia da autoridade; rotinas. Pode-se considerar que esta é uma visão muito defasada quando a contrastamos com a administração moderna, voltada para administração de resultados, utilizando os inúmeros recursos disponíveis como o avanço tecnológico, o fluxo de informações e principalmente o desenvolvimento de pessoas. (CHIAVENATO, 2000).

\subsection{Compras na Administração Pública}

Conforme estabelece a Constituição Federal em seu artigo 37, as compras na Administração Pública, ressalvados os casos especificados na legislação, deverão ser realizadas mediante 


\section{Sustainable Business International Journal}

processo de licitação pública que assegure igualdade de condições a todos os concorrentes. A Lei 8.666/1993 regulamenta o art. 37, inciso XXI, da Constituição Federal, instituindo as normas para licitações e contratos da Administração Pública. O critério de utilização de cada modalidade geralmente está vinculado ao valor estimado da contratação. Para fins de objetividade será dado um enfoque maior a modalidade de licitação Pregão, pois esta é a mais utilizada para aquisição de bens materiais, que é o foco deste estudo.

\footnotetext{
“Licitação é o procedimento mediante o qual a Administração pública seleciona a proposta mais vantajosa para o contrato de seu interesse. Como procedimento, desenvolve-se através de uma sucessão ordenada de atos vinculantes para a administração e para os licitantes, o que propicia igual oportunidade a todos os interessados e atua como fator de eficiência e moralidade nos negócios administrativos. " (MEIRELLES, 2007, p. 272 - 273).
}

Segundo a Lei 8.666/93 e Decreto 3.555/2000, são modalidades de licitação:

Concorrência: é a modalidade de licitação entre quaisquer interessados que, na fase inicial de habilitação preliminar, comprovem possuir os requisitos mínimos de qualificação exigidos no edital para execução de seu objeto.

Tomada de preços: é a modalidade de licitação entre interessados devidamente cadastrados ou que atenderem a todas as condições exigidas para cadastramento até o terceiro dia anterior à data do recebimento das propostas, observada a necessária qualificação. 


\section{Sustainable Business International Journal}

Convite: é a modalidade de licitação entre interessados do ramo pertinente ao seu objeto, cadastrados ou não, escolhidos e convidados em número mínimo e 3 (três), pela unidade administrativa, a qual afixará, em local apropriado, cópia do instrumento convocatório e o estenderá aos demais cadastrados na correspondente especialidade que manifestarem seu interesse com antecedência de até 24 (vinte e quatro) horas da apresentação das propostas.

Concurso: é a modalidade de licitação entre quaisquer interessados para escolha de trabalho técnico, científico ou artístico, mediante a instituição de prêmios ou remuneração aos vencedores, conforme critérios constantes de edital publicado na imprensa oficial com antecedência mínima de 45 (quarenta e cinco) dias.

Leilão: é a modalidade de licitação entre quaisquer interessados para a venda de bens móveis inservíveis para a administração ou de produtos legalmente apreendidos ou penhorados, ou para a alienação de bens imóveis prevista no art. 19, a quem oferecer o maior lance, igual ou superior ao valor da avaliação.

Pregão: é a modalidade de licitação em que a disputa pelo fornecimento de bens ou serviços comuns é feita em sessão pública, por meio de propostas de preços escritas e lances verbais. O Pregão é regulamentado nos termos da Lei $n^{\circ} 10.520$ / 2002, do Decreto $n^{\circ} 5.450 / 2005$, do Decreto $\mathrm{n}^{\mathrm{o}}$ 7.892/2013, da Instrução Normativa SLTI/MPOG $\mathrm{n}^{\circ} 2$ /2010, da Lei Complementar $n^{\circ}$ 123/2006, da Lei $n^{\circ} 11.488 / 2007$, do Decreto $n^{\circ}$ 6.204/ 2007, aplicando-se, 


\section{Sustainable Business \\ International Journal}

SBIJ72 - MARÇO DE 2017 - ISSN 1807-5908

subsidiariamente, a Lei ${ }^{\circ}$ 8.666, de 21 de junho de 1993.

Na modalidade Pregão Eletrônico, uma das práticas mais adotadas é o Sistema de Registro de Preços - SRP - conjunto de procedimentos para registro formal de preços relativos à prestação de serviços e aquisição de bens, para contratações futuras. O SRP poderá adotado nas seguintes hipóteses: quando, pelas características do bem ou serviço, houver necessidade de contratações frequentes; quando for conveniente a aquisição de bens com previsão de entregas parceladas ou contratação de serviços remunerados por unidade de medida ou em regime de tarefa; quando for conveniente a aquisição de bens ou a contratação de serviços para atendimento a mais de um órgão ou entidade, ou a programas de governo ou quando, pela natureza do objeto, não for possível definir previamente o quantitativo a ser demandado pela Administração. (Decreto n ${ }^{\circ}$ 7.892/2013).

Na modalidade de Licitação Pregão - que poderá ser presencial, mas preferencialmente deverá ser adotada sua forma eletrônica - a avaliação da proposta deverá ser realizada de forma objetiva considerando somente os critérios técnicos estabelecidos previamente em edital. São critérios para julgamento de propostas: menor preço, melhor técnica e melhor técnica e preço (BARBIERI E MACHLINE, 2009). 


\section{Sustainable Business \\ International Journal}

SBIJ72 - MARÇO DE 2017 - ISSN 1807-5908

\begin{tabular}{|c|c|c|}
\hline Modalidade & Obras de Serviços de Engenharia & Bens e Serviços Comuns. \\
\hline Concorrência & $\begin{array}{l}\text { Contratações com valor superior a } \\
\qquad \mathrm{R} \$ 1.500 .000,00\end{array}$ & $\begin{array}{l}\text { Contratações com valor superior a } \\
\qquad \mathrm{R} \$ 650.000,00\end{array}$ \\
\hline Tomada de Preços & $\begin{array}{l}\text { Contratações com valor até } \\
\qquad \mathrm{R} \$ 1.500 .000,00\end{array}$ & $\begin{array}{l}\text { Contratações com valor até } \\
\qquad \mathrm{R} \$ 650.000,00\end{array}$ \\
\hline Convite & $\begin{array}{l}\text { Contratações com valor até } \\
\qquad \mathrm{R} \$ 150.000,00\end{array}$ & $\begin{array}{l}\text { Contratações com valor até } \\
\qquad \mathrm{R} \$ 80.000,00\end{array}$ \\
\hline Leilão & \multicolumn{2}{|c|}{$\begin{array}{l}\text { Venda de bens móveis inservíveis para a administração ou de produtos } \\
\text { legalmente apreendidos ou penhorados, ou para a alienação de bens imóveis, } \\
\text { a quem oferecer o maior lance, igual ou superior ao valor da avaliação. }\end{array}$} \\
\hline Concurso & \multicolumn{2}{|c|}{$\begin{array}{l}\text { Escolha de trabalho técnico, científico ou artístico, mediante a instituição de } \\
\text { prêmios ou remuneração aos vencedores. }\end{array}$} \\
\hline Pregão & \multicolumn{2}{|c|}{$\begin{array}{l}\text { Contratação de bens e serviços comuns, que compreendem aqueles cujos } \\
\text { padrões de desempenho e qualidade possam ser objetivamente definidos } \\
\text { pelo edital, por meio de especificações usuais no mercado. }\end{array}$} \\
\hline
\end{tabular}

Quadro1 - Adaptação,2016

Fonte: Lei n ${ }^{\circ} 8.666 / 1993$ e Lei n ${ }^{\circ} 10.520 / 2002$

São ainda formas de contratação a Inexigibilidade de Licitação e a Dispensa de Licitação. Geralmente é inexigível a licitação quando há inviabilidade de competição e nas situações elencadas no Art. 25 da Lei $n^{\circ}$ 8.666/1993. Já a Dispensa de Licitação ocorre por vários motivos tais como: nos casos de guerra ou grave perturbação da ordem, compras de pequeno valor no limite de $\mathrm{R} \$ 8.000,00$. Neste último caso a utilizada a Cotação Eletrônica.

\section{LOGÍSTICA HOSPITALAR - CONCEITOS GERAIS}

Para Santos (2006), o gerenciamento dos estoques de um hospital deve garantir o abastecimento eficiente de medicamentos e materiais necessários ao pleno funcionamento da 


\section{| Sustainable Business}

SBIJ72 - MARÇO DE 2017 - ISSN 1807-5908

unidade de saúde, atendendo a duas grandes exigências básicas: não haver faltas ou excessos. Defende também que o fluxo logístico integra todos os departamentos do hospital que fazem interface com o processo de dispensação de medicamentos e insumos hospitalares.

\footnotetext{
“Uma organização de saúde é um sistema produtivo de atenção à saúde, onde o setor de abastecimento integra-se como subsistema para atender as necessidades de insumos (materiais de consumo) e de equipamentos (materiais permanentes) daqueles que desenvolvem e disponibilizam os produtos, que são os profissionais de saúde. "(INFANTE e SANTOS, 2007).
}

Wolf (2002) afirma que a atual cadeia de abastecimento da saúde é um sistema complexo com múltiplas camadas de organizações e processos com vários intermediários entre o fabricante e o consumidor final (paciente).

As atividades de uma Unidade Hospitalar são complexas, independentemente de seu perfil de atendimento - alta / média complexidade ou atenção básica. A insuficiência de materiais e medicamentos é um dos pontos que mais preocupam os gestores dos serviços de saúde. $\mathrm{Na}$ Administração Pública uma série de fatores contribui para dificultar a gestão de materiais, tais como: restrição orçamentária, falta de profissionais qualificados na área administrativa, falta de integração entre a área administrativa e a área assistencial para conclusão das aquisições e seleção de materiais, sistemas de gestão de estoque confusos ou não funcionais. É fundamental que as unidades de saúde aprimorem seus sistemas de gestão de materiais, visando a garantia de um atendimento ininterrupto e de qualidade, com o menor custo 


\title{
Sustainable Business \\ International Journal
}

SBIJ72 - MARÇO DE 2017 - ISSN 1807-5908

possível.

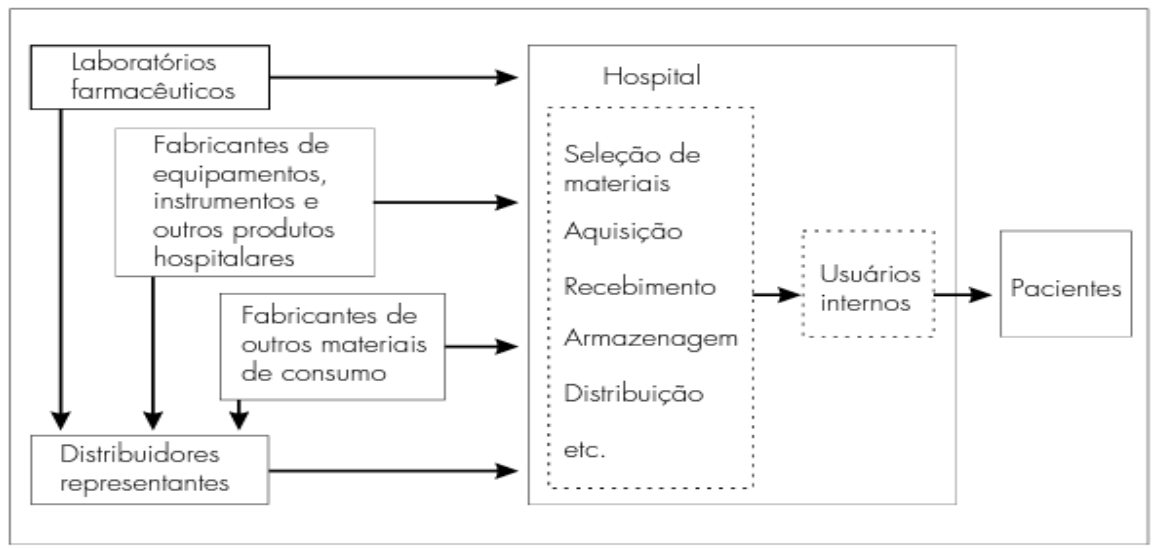

Figura 1: Cadeia de Suprimentos de um hospital,2016

Fonte: Barbieri e Machline, 2006.

\begin{abstract}
"As atividades típicas de suprimento são, entre outras, as seguintes, seleção de materiais, compras, recebimento de materiais, gestão de estoques, armazenagem, distribuição e atendimento aos usuários internos. Num hospital as principais atividades são as mesmas, com as especificidades que as questões hospitalares requerem.” (BARBIERI E MACHLINE, 2006, p. 21).
\end{abstract}

O planejamento estratégico é condição sine qua non para uma gestão eficiente da cadeia de suprimentos. Planejando estrategicamente é possível criar condições para linhas de ação, deixando margem para atuação em momentos de crise ou em momentos de aquisições emergenciais - muito comuns quando tratamos de Unidades de Saúde. Baseado na literatura apresentada, é possível afirmar que as atividades de suprimentos estão diretamente 


\section{$\mid$ Sustainable Business}

SBIJ72 - MARÇO DE 2017 - ISSN 1807-5908

relacionadas, tendo impacto direto uma sobre as outras quando ocorre falha em algum elo da cadeia.

Barbieri e Machline (2006) elencam as atividades mais comuns da cadeia de suprimentos:

Seleção de Materiais: envolve atividades de especificação de materiais, padronização e definição de critérios para adotar novos materiais e substituir os que estão sendo usados.

Gestão de Estoques: tem como objetivo a realização de previsão de demandas, montagem e operação de sistemas de reposição de estoque.

Compras e Aquisições: são as atividades voltadas para seleção, avaliação e desenvolvimento de fornecedores, negociação e acompanhamento das compras.

Armazenagem: tem como atividades o recebimento, guarda e distribuição aos usuários internos.

Respeitando a proposta inicial do artigo e a delimitação do tema, será apresentado, mais detalhadamente, a importância e as principais dificuldade enfrentadas pelo setor responsável por compras. 


\title{
4.2 Funções e Dificuldades do Setor de Compras na Administração Pública
}

Costa conceitua compra:

\begin{abstract}
"Uma função administrativa, dentro da organização, responsável por coordenar um sistema de informação e controle capaz de adquirir externamente, para garantir o fluxo de materiais necessários à missão da organização, bens e serviços na quantidade certa, na qualidade certa, da fonte certa, no exato momento e ao preço certo. " (COSTA, 2000, p. 119.)
\end{abstract}

Em um sentido mais amplo, pode-se concluir que um setor de compras tem como objetivo primordial a aquisição de bens / serviços na quantidade e qualidade desejada, no momento exato e ao menor custo possível. O Setor de Compras é, na realidade, um prestador de serviços dentro da Instituição, que visa atender a demanda dos requisitantes. Para Mecinas um Setor de Compras visa atender aos seguintes objetivos:

\footnotetext{
"Movimentar é controlar o fluxo de dinheiro da melhor maneira possível, em virtude das compras representarem um investimento; servir eficazmente na consecução de matérias primas e artigos indispensáveis a fabricação, comercialização de produtos ou serviços, afim de manter a empresa competitivamente em operação, ou seja, interpretar de maneira efetiva as metas da empresa”. (MECINAS, 1999, p. 06).
}

Sobretudo em Unidades Hospitalares, o custo não deve ser a principal variável no momento do fechamento da compra. Não é aconselhável que o menor preço prevaleça em detrimento da qualidade, sobretudo tratando-se de materiais médicos / medicamentos. Desta forma, o comprador deve sempre solicitar um parecer técnico conclusivo aos setores demandantes, 


\section{Sustainable Business International Journal}

mesmo que a compra pareça, em um primeiro momento, economicamente mais vantajosa, pois geralmente compradores são profissionais administrativos, ou seja, não possuem cabedal técnico para avaliar qualidade de tais insumos.

Dias e Costa (2012) elencam os principais problemas na área de compras, que podem ser reconhecidos tanto no âmbito privado quanto na Administração Pública:

Compras de Emergência: Ocorrem, geralmente, em função da falta de planejamento por parte dos demandantes. Compras emergenciais dificultam muito a atuação do comprador em termos de negociação. Por esta razão, a consequência são preços mais elevados e até mesmo a falta do material. Compras de emergência sempre existirão, entretanto, é preciso traçar estratégias para diminuir tal ocorrência para que não haja comprometimento no funcionamento da Instituição.

Especificações Incorretas: O material não é bem especificado pelo requisitante, gerando dúvidas por parte do comprador e até mesmo do fornecedor. Uma especificação mal feita provoca atraso na conclusão da aquisição.

Burocracia Excessiva: O Setor de Compras não gerencia diretamente os recursos, mas geralmente está envolvido em grandes movimentações financeiras. Tratando-se de Administração Pública o controle é - ou deveria ser - ainda mais rigoroso. Entretanto este controle não deve ser uma forma de dificultar as aquisições. O Setor Público já conta com 


\section{Sustainable Business \\ International Journal}

SBIJ72 - MARÇO DE 2017 - ISSN 1807-5908

legislação específica que disciplina as etapas que um processo de aquisição deve seguir. Cabe aos gestores organizar os fluxos de tal legislação para que as atividades se tornem as mais ágeis possíveis.

Ingerência: É comum nas instituições os demandantes acreditarem que podem comprar melhor que qualquer profissional de compras, desconsiderando que a compra para pessoa física é distinta de uma compra para uma organização inteira. Muitas vezes a interferência direta dos setores requisitantes em etapas que não são de sua competência retardam as aquisições, além de gerar custos mais elevados e até mesmo desnecessários.

\section{ESTUDO DE CASO - EXEMPLIFICAÇÃO DAS FALHAS DE ABASTECIMENTO NO SETOR DE FARMÁCIA DE UMA INSTITUIÇÃo PÚBLICA.}

Este estudo de caso será utilizado para ilustrar as dificuldades de abastecimento de um Setor de Farmácia em uma instituição pública e que estão diretamente relacionadas ao setor responsável pelas compras, utilizando como fonte de informações dados secundários, coletados em entrevistas com pessoas do próprio setor, consultas a documentos e sistemas oficiais da instituição. O estudo de caso será focado em melhorias de curto prazo nas atividades básicas relacionadas à otimização do abastecimento, ocasionando melhor gestão dos procedimentos e dos recursos financeiros, e fatalmente o melhor atendimento ao paciente. O objetivo é evitar o desperdício e, principalmente, diminuir as ocorrências negativas, 


\section{Sustainable Business International Journal}

evitando que ocorra paralisação de atendimentos por falta de medicamentos.

Contextualizando o cenário, é preciso esclarecer que na Instituição hospitalar estudada, o Setor de Farmácia é um cliente interno do Setor de Compras, assim como os pacientes e os profissionais são clientes internos do Setor de Farmácia.

O sistema de logística das farmácias hospitalares é bastante complexo. O setor de farmácia da instituição tem como atividade a gestão do estoque que envolve, em suas atividades operacionais, o recebimento, conferência, estocagem, dispensação e, atualmente, rastreabilidade. Em suas atividades estratégicas estão planejamento por meio do cruzamento de dados de distribuição e estoque, visando uma reposição de material eficiente. Além do que podemos chamar de Farmácia Central, existe ainda um projeto de implantação de um estoque satélite com medicamentos utilizados no Centro Cirúrgico.

Entre as principais reclamações por parte do Setor de Farmácia, contribuem para uma má gestão do estoque: falta de um sistema informatizado gerencial de controle de estoques, o tempo necessário para a compra dos insumos - desde o pedido inicial de compra até o recebimento do medicamento - falta de espaço físico para armazenagem de solução de grandes volumes, falta de colaboradores administrativos para cumprimento de controles rígidos e cumprimento de metas que visam à segurança do paciente. Geralmente as farmácias hospitalares trabalham com altos níveis de estoque, em virtude da diversidade de produtos e da peculiaridade de cada paciente, dificultando o planejamento de ressuprimento. 


\section{Sustainable Business International Journal}

Alguns fatores são de solução de médio e longo prazo, como a adoção de um novo sistema informatizado de controle de estoque e a adequação do espaço físico. A primeira situação depende da mudança de toda uma rede, pois o SUS não opera de forma isolada, ou seja, um único hospital não pode funcionar com um sistema próprio e sim são adquiridos sistemas para toda uma rede. O segundo depende de adequação do espaço, poderiam ser necessárias obras de adequação. Em ambos os casos deveriam ser feitas licitações.

A sugestão de melhoria que pode ser relacionada diretamente ao Setor de Compras transita, essencialmente, na questão operacional, ou seja, de fácil adaptação e resultados rápidos. No que se refere o tempo necessário para a compra dos insumos, acredita-se que há um excesso de burocracia. Entretanto, analisando o exposto, percebe-se que o que ocorre, fundamentalmente, é a falta de planejamento. A carência de um planejamento gera, entre outras situações, as compras de emergência.

Algumas ações operacionais simples poderiam ser adotadas pelo Setor de Farmácia e pelo Setor de Compras de forma conjunta, gerando impacto positivo a curto prazo na Instituição e, consequentemente, maior eficiência no abastecimento. Dias e Costa (2012). Pode-se sugerir:

Conscientização dos requisitantes: Muitas vezes os responsáveis pelas solicitações dos pedidos de emergência não têm muita informação acerca dos procedimentos necessários para realizar aquisições, tão pouco suas consequências negativas no que se refere a custo e disponibilidade do material. O esclarecimento e a conscientização dos responsáveis tem efeito 


\section{Sustainable Business \\ International Journal}

SBIJ72 - MARÇO DE 2017 - ISSN 1807-5908

rápido, pois ocorre uma mudança de comportamento. É importante avaliação periódica sobre essa mudança de atitude. É uma ação que precisa ser reforçada de tempos em tempos.

Controles de estoques mais rígidos: A conscientização e a diminuição dos pedidos de emergência estão diretamente atrelados a controles de estoque e de procedimentos. É um equívoco associar a existência de controles de estoque a um excesso de burocracia. Controles apontam erros de processos, permitindo suas correções e avaliação de eficácia.

Estabelecimento de prioridades de atendimento: Muitas requisições que são encaminhadas ao setor de compras não são tão urgentes. Pode parecer absurdo, mas alguns profissionais utilizam seu nível hierárquico para impor prioridade. É preciso que o Setor de Farmácia faça uma triagem inicial diferenciando a importância das pessoas e a importância do problema real.

Elaboração de planejamento próprio e participação no planejamento global da Instituição: os profissionais atuam na fase de execução de tarefas. Ocorre que, muitas vezes, o departamento é simplesmente excluído do macroplanejamento da organização. O departamento responsável pelas aquisições deve ser envolvido em todas as fases do planejamento: na estratégica, na tática e na operacional. Não planejar internamente as tarefas torna impraticável o alcance de metas mais simples.

Investimento em capital humano: geralmente os departamentos de compras contam quadros 


\section{Sustainable Business International Journal}

de profissionais muito reduzidos. Há muito mais aquisições para se realizar do que profissionais para executar. Por esta razão é imprescindível o investimento em treinamentos para que os profissionais, mesmo que insuficientes, sejam os mais bem preparados possíveis.

Criação de canais de comunicação junto aos requisitantes: por vezes os clientes internos profissionais da instituição - elaboram seus pedidos e não tem qualquer retorno. A falta de comunicação gera frustração de expectativa, ocasionando muitas vezes pedidos em duplicidade, pois, se o requisitante não recebe resposta a respeito de sua solicitação, encaminha outros pedidos, até que tenha sucesso. Uma simples ação de retorno, como o envio de um e-mail, informando uma previsão de conclusão da aquisição traria um efeito positivo e uma imagem de eficiência, demonstrando que sua solicitação foi recebida e está sendo executada. Em outras palavras, a pessoa tem sua importância.

\section{CONSIDERAÇÕES FINAIS}

As dificuldades no que diz respeito a gestão de estoques e aquisições apresentadas na Administração Pública são similares as encaradas em empresas privadas. O diferencial está nos princípios e na finalidade. As palavras de ordem são estratégia, planejamento e integração. Esses pilares deveriam levar os gestores a mudar sua maneira de pensar. Não existe mais um pensamento restrito e sim uma visão holística, ação em rede. Ver a Instituição como um sistema. É uma ação complexa, pois envolve uma mudança de paradigma. Envolve a mudança de um modelo rígido. 


\section{Sustainable Business International Journal}

Ao contrário do que ocorre na iniciativa privada, em Instituições públicas as aquisições obedecem a leis e decretos, fundamentalmente à Lei $n^{\circ}$ 8.666/93. Apesar dessa diferença, a essência dos procedimentos de compra é parecida. Mesmo que lentamente, percebe-se que a Administração Pública passa por um processo de transformação na tentativa de uma reestruturação administrativa. Há um entendimento quanto à necessidade de mudança no sistema de compras públicas, objetivando mais eficiência, agilidade, e, principalmente, transparência.

A gestão de materiais e medicamentos é uma área especializada, que tem como finalidade disponibilizar o insumo certo no exato momento em que ele for necessário. Para que isso ocorra, em qualquer empresa, é fundamental que haja planejamento. Para geração de informações confiáveis é primordial planejar, controlar e organizar as necessidades. Em Instituições de saúde a atenção quanto ao planejamento, controle e organização deve ser redobrada, pois a falta de um insumo / medicamento poderá colocar em risco a vida do cidadão.

Salienta-se que a gestão de material médico hospitalar não tem recebido a devida atenção profissional. Os Setores ligados a gestão de materiais e medicamentos são colocados em segundo plano. As atividades primárias não são desenvolvidas com eficácia, não existe um controle do fluxo de materiais. Muitas vezes, conferem-se responsabilidades a colaboradores não qualificados para o exercício de suas funções. Também são frequentes as queixas em relação a falta de informatização de processos de controle. Quando uma gestão começa 


\section{Sustainable Business International Journal}

equivocada, é praticamente impossível que as compras - atividade meio - funcionem de forma efetiva. É imperioso investir em capital humano.

Em Instituições de Saúde a ocorrência de grandes estoques de alguns materiais e a carência de outros, é, talvez, um dos problemas cruciais para os profissionais envolvidos nos processos gerenciais e nos processos de compras. A carência ocasiona, muitas vezes, a interrupção do atendimento. Além da questão assistencial, estoque elevado é sinônimo de falha nos controles de estoque, e consequentemente mau aproveitamento do capital público.

Entre as sugestões de melhorias possíveis e de curto prazo estão a revisão de procedimentos internos, objetivando agilização dos processos de trabalho. O controle jamais poderá ser sinônimo de morosidade. $\mathrm{O}$ controle em procedimentos administrativos presenciado nos serviços de saúde no Brasil é apontado como uma das principais causas de desabastecimento. Outra variável sempre lembrada é insuficiência de recursos orçamentários. Entretanto, a falta de planejamento logístico e a escassez de profissionais qualificados, sim, deveriam ser apontados como falhas principais.

A evolução tecnológica tem levado ao aumento da complexidade assistencial, demando um nível de atenção cada vez maior, por parte dos profissionais de saúde. Cada procedimento de compra, apesar da tentativa de padronização, requer um conjunto específico de processos de trabalho, cuja composição pode variar em função dos tipos de procedimentos realizados, pacientes atendidos e até dos profissionais da Instituição. Os setores ligados ao abastecimento 


\section{Sustainable Business International Journal}

integram-se como um sistema para atender às necessidades de aquisição de insumos e de equipamentos. O objetivo é garantir a melhora na qualidade dos serviços de assistência, diminuindo custos de operação.

Felizmente o processo de compras já é entendido como área estratégica que influencia diretamente a missão da empresa e os custos da Instituição. Mesmo que tardiamente, as Instituições perceberam que o setor de compras é muito mais que um departamento. É preciso uma reflexão sobre ações internas, ou seja, o que as Organizações podem fazer para amenizar os impactos negativos no Setor. Algumas ações utilizadas na iniciativa privada, mesmo comprovadamente eficientes e eficazes, na maioria das vezes não podem ser adotadas na esfera pública por uma questão legal.

As Instituições Públicas são cada vez mais cobradas por serviços de qualidade. O cidadão / cliente está cada vez mais consciente de seus direitos e para que haja um serviço de fato eficiente é indispensável à formação de um quadro de colaboradores competentes, ou seja, bem preparados e motivados. Gradativamente a era da burocracia associada a morosidade será abolida em benefício da gestão por resultados. Termos antes utilizados apenas na iniciativa privada como comprometimento, iniciativa, desenvolvimento técnico ganham cada vez mais espaço no Setor Público. Os Servidores mostram-se receptivos a modernização e têm consciência de sua responsabilidade perante a sociedade. 


\section{REFERÊNCIAS BIBLIOGRÁFICAS}

BALLOU, R.H. Gerenciamento da Cadeia de Suprimentos/Logística Empresarial. $5^{\text {a }}$ ed. Porto Alegre: Bookman, 2006.

BARBIERI, J.C; MACHLINE, C. Logística Hospitalar. Teoria e Prática. $2^{\mathrm{a}}$ ed. São Paulo: Saraiva, 2006.

BRASIL. Constituição da República Federativa do Brasil: promulgada em 5 de outubro de 1988. 38 ed. São Paulo: Saraiva, 2006.

BRASIL. Lei 8.666 de 21 de junho de 1993. Regulamenta o art. 37, inciso XXI, da Constituição Federal, institui normas para licitações e contratos da Administração Pública e dá outras providências.

BRASIL. Decreto N. 7.892, de 19 de março de 2010. Regulamenta os critérios e procedimentos gerais a serem observados para a realização das avaliações de desempenho individual e institucional e o pagamento das gratificações de desempenho.

CHIAVENATO, Idalberto. Administração nos Novos Tempos. São Paulo: Makron Books, 2000.

DIAS, Mário; COSTA, Roberto Figueiredo. Manual do Comprador: conceitos, técnicas e práticas indispensáveis em um departamento de compras. São Paulo: Saraiva, 2012.

CHIAVENATO, Idalberto. Administração: teoria processo e prática. 2. Ed. São Paulo: Makron Books, 1994.

KOTLER, Philip. Princípios de Marketing. Rio de Janeiro: LTC, 1998.

MECINAS, Leonel Cruz. Compras, Princípios Gerais. $2^{\circ}$ Edição. Madri: Companhia Editorial Continental S.A. d CV, 1999 


\section{Sustainable Business International Journal}

MEIRELLES, Hely Lopes. Direito Administrativo Brasileiro. 16. Ed. São Paulo: RT, 1990.

INFANTE, M; SANTOS, M. A. B. A organização do abastecimento do hospital público a partir da cadeia produtiva: uma abordagem logística para a área de saúde. Ciência \& Saúde Coletiva , Vol. 12, n. 4, pp. 945-954, 2007.

SALU, Ênio Jorge. Administração hospitalar no Brasil. São Paulo: Manole, 2014. 